\title{
Function and Immunochemistry of Prekallikrein-High Molecular Weight Kininogen Complex in Plasma
}

\author{
Cheryl F. ScotT and Robert W. Colman, Coagulation Unit, \\ Hematology-Oncology Section, Department of Medicine, \\ University of Pennsylvania, Philadelphia, Pennsylvania 19104
}

A B S T R A C T Plasma from individuals with high molecular weight (HMW) kininogen deficiency has been reported to be deficient in prekallikrein as measured by radial immunodiffusion, prekallikrein coagulant activity, and/or kaolin-activated arginine esterase activity. The discovery that prekallikrein and HMW kininogen circulate as a complex in plasma led us to reevaluate the antigenic and functional properties of prekallikrein in HMW kininogen-deficient plasma as well as in normal plasma.

The low prekallikrein antigen level in an individual with HMW kininogen deficiency was corrected to the normal range (80-95\%) by the addition of $0.2 \mathrm{U} / \mathrm{ml}$ of purified HMW kininogen. A similar increase in apparent prekallikrein antigen was observed when purified prekallikrein and HMW kininogen were combined. The correction of the apparent prekallikrein defect in this HMW kininogen-deficient plasma coincided with the formation of a prekallikrein-HMW kininogen complex as demonstrated by immunoelectrophoresis. Similar findings were demonstrated with purified prekallikrein and HMW kininogen by immunoelectrophoresis as well as crossed immunoelectrophoresis.

The coagulant activity in HMW kininogen-deficient plasma was increased in a dose-dependent manner by the addition of HMW kininogen, reaching $85 \%$ of normal level at a concentration of $0.2 \mathrm{U} / \mathrm{ml}$. Kaolin-activated arginine esterase activity (kallikrein) in HMW kininogen-deficient plasma was fully corrected when HMW kininogen was added to the deficient plasma after depletion of kallikrein inhibitors. The functional and antigenic concentration of prekallikrein in plasma from four other HMW kininogen-deficient individuals was similarly corrected to normal after adding HMW kininogen.

This work was presented in part at the International Symposium on Kinins, Tokyo, Japan, 8 November 1978 and published as in abstract form: 1979. Clin. Res. 27: 460A.

Dr. Scott's and Dr. Colman's present address is Specialized Center for Thrombosis Research, Temple University Health Sciences Center, Philadelphia, Pa. 19140.

Received for publication 23 January 1979 and in revised form 20 September 1979.
Addition of HMW kininogen increased the apparent prekallikrein activity in native normal plasma (as measured by esterase activity) but not in normal plasma in which inhibitors were inactivated. The apparent prekallikrein antigen concentration (as measured by radial immunodiffusion or electroimmunodiffusion) increased upon addition of HMW kininogen. Immunoelectrophoresis as well as gel filtration of normal plasma revealed the presence of free prekallikrein (17-38\% of the total) in addition to the HMW kininogen-prekallikrein complex previously reported.

This study emphasizes the influence of HMW kininogen on both functional and immunologic determinations of prekallikrein.

\section{INTRODUCTION}

Plasma from individuals with severe deficiency of high molecular weight kininogen (HMW kininogen) ${ }^{1}$ have abnormalities in all Factor XII-dependent pathways including coagulation, kinin formation, fibrinolysis, and permeability enhancement (1-5). Associated prekallikrein deficiency, although insufficient to account for these abnormalities, has been described in all but one of these individuals (3). Close functional relationships, however, do exist between these two proteins. The activated form of prekallikrein, kallikrein, is the enzyme which releases bradykinin from HMW kininogen (6), whereas HMW kininogen in turn potentiates the activation of prekallikrein on a surface by Factor XII $(7,8)$ or in the fluid phase by Factor XII fragments $\left(\mathrm{XII}_{\mathrm{f}}\right)(9)$. The former activity may involve the increased binding of prekallikrein to the surface when complexed with HMW kininogen. The intimate physical and functional interrelations between these two proteins suggested that the assay methods used for prekallikrein

${ }^{1}$ Abbreviations used in this paper: B-2, sodium barbital buffer, pH 8.6; Cî-inhibitor, CîS-inactivator; EID, electroimmunodiffusion; HMW kininogen, high molecular weight kininogen; $\mathrm{XII}_{\mathrm{f}}$, Factor XII fragments; IEP, immunoelectrophoresis; RID, radial immunodiffusion; TAMe, $p$-tosyl-Larginine methyl ester. 
may be affected by the presence or absence of HMW kininogen and give rise to an apparent deficiency of prekallikrein in HMW kininogen-deficient plasma.

This study provides evidence that both immunochemical and functional assays are thus influenced and that the addition of purified HMW kininogen to plasma congenitally deficient in that protein corrects not only the defects in the Factor XII-dependent pathways, but also results in normalization of the apparent prekallikrein deficiency. Furthermore, the nature of prekallikrein in normal plasma has also been reinvestigated, both functionally and immunochemically. Plasma prekallikrein was found to exist in two forms, the major portion complexed to HMW kininogen as well as a minor component in an uncomplexed state.

\section{METHODS}

Materials. Antisera to immunoglobulin (Ig)G, CīS-inactivator $\left(\mathrm{C} \overline{1}\right.$-inhibitor), $\alpha_{1}$-antitrypsin, $\alpha_{2}$-macroglobulin, antithrombin III, and radial immunodiffusion (RID) plates for IgG (L-C Partigen [Behring Diagnostics, American Hoechst Corp., Sommerville, N. J.]). H-D-Pro-Phe-Arg-p-nitroanilide-HCl (S-2302, Ortho Diagnostics Inc., Raritan, N. J.) was used as a synthetic substrate of kallikrein. Tris and $p$-tosyl-L-arginine methyl ester (TAMe [Sigma Chemical Co., St. Louis, Mo.]); kaolin (Fisher Scientific Co., Pittsburgh, Pa.); HSA agarose (Litex-Denmark); sodium barbital buffer, pH 8.6 (B-2) (Harleco, American Hospital Supply Corp., Gibbstown, N. J.); Coomassie Brilliant Blue R250 (Bio-Rad Laboratories, Richmond, Calif.); inosithin (Associated Concentrates, New York); Sephadex G-200, QAE-Sephadex, A-50, CM-Sephadex, C-50, and SP-Sephadex, C-50, (Pharmacia Fine Chemicals, Div. of Pharmacia Inc., Piscataway, N. J.); anti-IgG agarose (Miles Laboratories, Inc., Elkhart, Ind.); were purchased from the designated supplier. All other reagents used were reagent grade.

Plasma. Normal human plasma was obtained from healthy donors, with their written informed consent, as previously described (9) and frozen in 1-ml portions. In the experiments where fresh plasma was used, it was collected in a similar manner and used within 30 min after collection.

Prekallikrein-deficient plasma was purchased from Dr. C. Abildgaard (University of California, Davis, Calif.). Factor XI-deficient plasma was purchased from George King Biomedical (Overland Park, Kan.). Factor XII-deficient plasma was obtained from an individual with congenital deficiency having a level of $<0.01 \mathrm{U} / \mathrm{ml}$. Plasma from HMW kininogendeficient individuals $(<0.02 \mathrm{U} / \mathrm{ml})$ was kindly supplied by Dr. Thomas Waldman (Fitzgerald), Dr. Virginia Donaldson (C.W. and Mack), and Dr. Kirk Wuepper (Flaujeac). Ms. M. Williams donated plasma directly to us.

Preparation of plasma proteins. Prekallikrein was prepared by a new procedure employing QAE-Sephadex, SPSephadex, and anti-IgG-agarose (10). The preparation was purified $1,800-$ fold with a specific activity of $31 \mu \mathrm{mol}$ TAMe hydrolyzed/min per $\mathrm{mg}$ protein. No detectable factor XI, Factor XII, HMW kininogen, plasmin, $\boldsymbol{\beta}_{2}$-glycoprotein I, Cī-inhibitor, $\alpha_{2}$-macroglobulin, antithrombin III, $\alpha_{1}$-antitrypsin, or IgG were present in the final preparation. The prekallikrein ran as a single band of 88,000 daltons on reduced or nonreduced sodium dodecyl sulfate disc gel electrophoresis (11). In some experiments, the prekallikrein used was obtained from the step before the anti-IgG agarose step and had IgG as the sole detectable impurity. No differences were noted between these two fractions regarding functional or immunologic activity. Antiserum to kallikrein completely neutralized the amidolytic activity of the activated enzyme. Kallikrein was prepared by incubating $50 \mu \mathrm{l}$ of the prekallikrein described above $(1 \mathrm{U} / \mathrm{ml})$ with $10 \mu \mathrm{l} \mathrm{XII}(50 \mu \mathrm{g} / \mathrm{ml})$ at $37^{\circ} \mathrm{C}$ for $8 \mathrm{~min}$.

HMW kininogen was purified by a modification of the method of Habal and Movat (12) by employing chromatography on QAE-Sephadex, ammonium sulfate precipitation, chromatography on CM-Sephadex and chromatography on SPSephadex. An additional step was added to the published procedure. A $2.5 \times 60-\mathrm{cm}$ column containing SP-Sephadex was equilibrated with $0.03 \mathrm{M}$ sodium acetate buffer, $\mathrm{pH} 6.0$, containing $0.05 \mathrm{M} \mathrm{NaCl}$. After application of the $\mathrm{HMW}$ kininogen from the CM-Sephadex steps and washing with the starting buffer, a linear gradient from 0.2 to $0.4 \mathrm{M} \mathrm{NaCl}$ in the same buffer was used to elute the HMW kininogen. The purified HMW kininogen emerged near the end of the gradient and had a specific activity of $15 \mathrm{U} / \mathrm{mg}$ coagulant activity. The protein was a single component of 120,000 daltons on sodium dodecyl sulfate-disc gel electrophoresis. No contamination was detected by functional assays for Factor XI, Factor XII, or prekallikrein coagulant activity, or by immunological assays for $\alpha_{2}$-macroglobulin, Cî-inhibitor, antithrombin III, $\alpha_{1}$ antitrypsin, or kallikrein.

The Factor XII fragments were prepared as described previously (13). No contamination with Factor XII or high molecular weight activator (13) was detected in purified XII $_{\mathrm{f}}$. There was no detectable contamination with Factor XI, plasminogen, plasmin, HMW kininogen, prekallikrein, or kallikrein. For use in functional studies, $\mathrm{XII}_{\mathrm{f}}$ was stabilized with bovine serum albumin at a final concentration of $0.5 \mathrm{mg} / \mathrm{ml}$.

Kallikrein was prepared by the method of Bagdasarian et al. (14). It contained no detectable HMW kininogen, Cİ-inhibitor $\alpha_{2}$-macroglobulin, $\alpha_{1}$-antitrypsin, plasminogen, or plasmin but contained 8\% IgG. This kallikrein preparation was used only for the production of antiserum. Antiserum to kallikrein was prepared in rabbits by the method of Bagdasarian et al. (14). It was adsorbed with prekallikrein-deficient plasma to render it monospecific.

\section{Immunological methods}

Electroimmunodiffusion EID. This was performed according to the method of Laurell (15) using $1 \%$ agarose in B-2, $\Gamma / 2=0.0375$. Kallikrein antiserum was used at a final concentration of $1.6 \%$. Electrophoresis was performed for $16 \mathrm{~h}$ at $14^{\circ} \mathrm{C}$ at $50 \mathrm{~V}$. The plates were soaked and stained as previously described (16).

Radial immunodiffusion. RID was performed according to the method of Mancini et al. (17) using $1 \%$ agarose in B-2, $\Gamma / 2=0.0375$. Kallikrein antiserum was used at a final concentration of $3 \%$. Diffusion proceeded for $24 \mathrm{~h}$. No further increase in ring diameter was observed at 48 or $72 \mathrm{~h}$.

Immunoelectrophoresis (IEP). Samples were run 1.5-4 h at $14^{\circ} \mathrm{C}$ at $250 \mathrm{~V}$. The buffer was B-2, $/ 2=0.0375$ in the running chamber as well as in the $1 \%$ agarose gel. After electrophoresis, the troughs were filled with $100 \mu \mathrm{l}$ of antikallikrein antiserum, diluted in saline. Diffusion occurred for $24 \mathrm{~h}$ in a humid chamber $\left(25^{\circ} \mathrm{C}\right)$.

Crossed IEP. Electrophoresis in the first dimension was performed for $3.5 \mathrm{~h}$ at $250 \mathrm{~V}$ at $14^{\circ} \mathrm{C}$ using the same buffer and agarose described for IEP. Dimension two was run for $16 \mathrm{~h}$ at $14^{\circ} \mathrm{C}$ at $50 \mathrm{~V}(15)$.

Preparation of samples for these immunological procedures involved the mixing of prekallikrein or plasma with B-2 buffer, $\Gamma / 2=0.0375$, or HMW kininogen. The samples were incubated either at $25^{\circ}$ or $37^{\circ} \mathrm{C}$ for $10 \mathrm{~min}$ before assay.

Assays of prekallikrein and kallikrein. Prekallikrein co- 
agulant activity was measured by preparing a standard curve from normal pooled plasma diluted in sodium barbital buffer in saline, $\mathrm{pH}$ 7.4. The dilutions ranged from $1 / 40$ to $1 / 320$. Two assay procedures, differing in order of addition of reagents, were used. In procedure A, $50 \mu$ l of diluted sample plasma was added to $50 \mu \mathrm{l}$ of a mixture containing $0.1 \%$ inosithin in $0.15 \mathrm{M} \mathrm{NaCl}$ and $10 \mathrm{mg} / \mathrm{ml}$ kaolin. $50 \mu \mathrm{l}$ of prekallikrein-deficient plasma was introduced and the mixture was then incubated for $1 \mathrm{~min}$ at $37^{\circ} \mathrm{C}$ before recalcification with $50 \mu$ l of $0.025 \mathrm{M} \mathrm{CaCl}_{2}$. Note that in this method the HMW kininogen present in prekallikrein-deficient plasma is not allowed to interact with the prekallikrein in the sample plasma until that plasma is exposed to kaolin. In the reconstitution experiments with HMW kininogen, the samples to be assayed were first diluted with sodium barbital buffer in saline, $\mathrm{pH}$ 1.4, and then added to purified HMW kininogen or additional buffer. The samples were incubated for $10 \mathrm{~min}$ at $25^{\circ} \mathrm{C}$ before adding them to the other reagents. They were then assayed similarly to the standard curve and expressed as the percent of normal pooled plasma. In procedure B, where samples containing free prekallikrein were assayed, they were allowed to come into contact with the prekallikrein-deficient plasma before kaolin addition. The results were similar to those obtained when the free prekallikrein sample was preincubated with purified HMW kininogen because prekallikrein-deficient plasma contains normal levels of HMW kininogen. There was no variation in results whether the sample was incubated briefly with the prekallikrein-deficient plasma, $(<10 \mathrm{~s})$ or as long as $10 \mathrm{~min}$.

In the esterolytic assay, samples were assayed for their ability to hydrolyze the synthetic substrate TAMe according to the method of Siegelman et al. (18) as modified by Colman et al. (19). Plasma was either incubated with $0.1 \mathrm{M}$ sodium

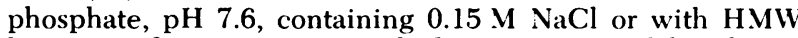
kininogen for $10 \mathrm{~min}$ at $25^{\circ} \mathrm{C}$ before activation of the plasma prekallikrein by kaolin.

Kallikrein inhibitors were depleted by either of two methods, using chloroform or acidification followed by neutralization (20). Without an activating agent, plasma prepared under these conditions hydrolyzed $<3 \mu \mathrm{mol} \mathrm{TAMe} / \mathrm{ml}$ per $\mathrm{h}$.

The amidolytic activity of kallikrein was determined using the chromogenic substrate H-D-Pro-Phe-Arg- $p$-nitroanilide$\mathrm{HCl}(21)$. The assay was modified by using $0.1 \mathrm{M}$ sodium phosphate buffer containing $0.15 \mathrm{M} \mathrm{NaCl}, \mathrm{pH} \mathrm{7.6,} \mathrm{and} \mathrm{sub-}$ strate at a final concentration of $0.09 \mathrm{mM}$.

Immunoassay for other proteins. L-C Partigen IgG plates for RID were used for the quantitative measurement of IgG according to the procedure described by the manufacturer.

Cì-inhibitor, $\alpha_{2}$-macroglobulin, antithrombin III, and $\alpha_{1}$ antitrypsin were quantitated by RID as described by Mancini et al. (17).

Assay of Factor XI, Factor XII, and HMW kininogen. These were measured by a modification of the partial thromboplastin time (22) using specifically deficient plasma as previously described (1). $1 \mathrm{U}$ is defined as that amount which is present in $1 \mathrm{ml}$ of normal pooled plasma.

\section{RESULTS}

Increasing concentrations of purified HMW kininogen were incubated with HMW kininogen-deficient plasma. Prekallikrein antigen was then assayed by both RID and EID (Fig. 1A). In the absence of HMW kininogen, this plasma contained, by these two assays, 35 and $20 \%$ prekallikrein antigen, respectively compared to normal pooled plasma used as a reference. The apparent pre-

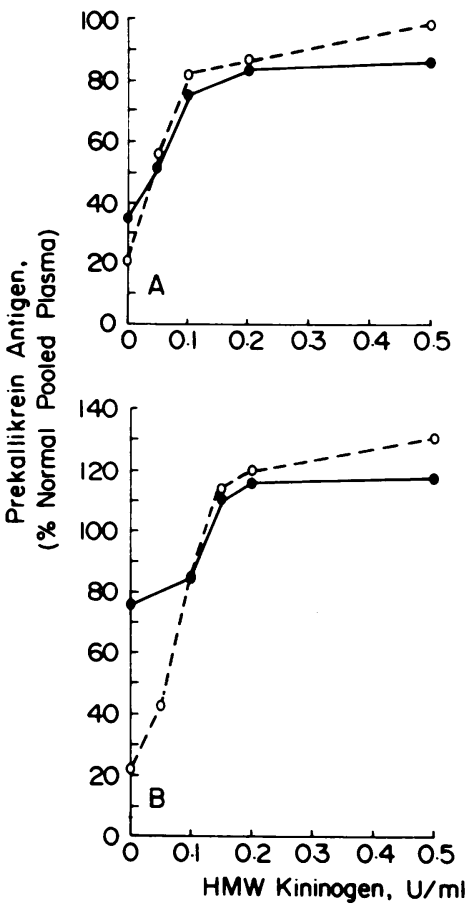

Figure 1 (A) Effect of HMW kininogen on the immunologic assays of plasma prekallikrein from a HMW kininogen-deficient individual. Plasma was incubated with B-2 buffer $(\Gamma / 2$ $=0.0375$ ) or purified $\mathrm{HMW}$ kininogen for $10 \mathrm{~min}$ at $37^{\circ} \mathrm{C}$ before assay by either RID or EID. A standard curve was prepared from an aliquot of normal pooled plasma. The values are expressed as percent of normal pooled plasma; (O) EID; (O) RID. (B) Effect of HMW kininogen on the immunologic assays for purified prekallikrein. $1 \mathrm{U} / \mathrm{ml}$ of purified prekallikrein was incubated with either buffer or H.MW kininogen and assayed as in Fig. 1A (O) EID; (O) RID.

kallikrein antigen increased three- to fourfold to a maximum between 80 and $95 \%$ of the normal pool in the presence of increasing concentrations of HMW kininogen. This maximum was attained at HMW kininogen concentrations between 0.1 and $0.2 \mathrm{U} / \mathrm{ml}$.

The evidence that this change was a result of the participation of only HMW kininogen and prekallikrein was elucidated by incubating purified prekallikrein in the absence and presence of purified H.MW kininogen (Fig. 1B). A progressive increase in apparent prekallikrein concentration was produced by the addition of increasing amounts of HMW kininogen to a fixed amount of purified prekallikrein. This increase was demonstrable in both RID and EID, but was more striking by EID because of the decreased electrophoretic mobility of prekallikrein antigen, at $\mathrm{pH} 8.6$, in absence of HMW kininogen. The maximal increase was observed at a concentration of $0.2 \mathrm{U} / \mathrm{ml} \mathrm{HMW}$ kininogen. Although the absolute concentration of prekallikrein antigen was the same before and after addition of HMW kininogen, the apparent prekallikrein concentration was greatly influenced by the presence of 
HMW kininogen. To demonstrate the basis of the increase observed, we studied prekallikrein antigen by IEP in plasma deficient in HMW kininogen as well as in normal plasma. A single precipitin arc near the origin was observed in HMW kininogen-deficient plasma (Fig. 2A). This arc was identical in position to purified prekallikrein or kallikrein (Fig. 2B) and therefore represented the position of free prekallikrein. In contrast in normal plasma, prekallikrein appeared as an elongated arc extending anodally. The anodal extension gave a reaction of identity with the free portion, and thus represented another form of this antigen. The anodal extension was reproduced in HMW kininogendeficient plasma by incubating the plasma with purified HMW kininogen (Fig. 2A) and was also formed by adding HMW kininogen to either purified prekallikrein or kallikrein (Fig. 2B). Thus, the anodal extension apparently represents a prekallikrein-HMW kininogen complex. Additions of HMW kininogen to normal plasma intensified the anodal section of the arc (HMW kininogen-prekallikrein complex) at the expense of the free prekallikrein arc. Similar results were obtained on crossed IEP of plasma (data not shown). The anodal arc increased in height and area as a function of the concentration of HMW kininogen added. Thus, in both normal and HMW kininogen-deficient plasma, addition of HMW kininogen resulted in the formation of a prekallikrein-HMW kininogen complex.

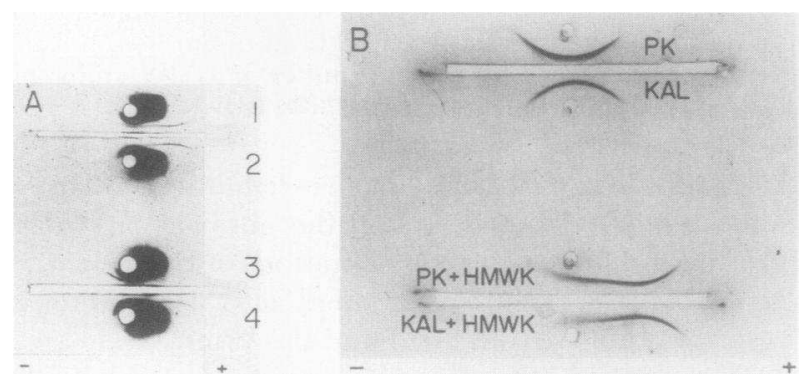

FIGURE 2 (A) IEP of normal and HMW kininogen-deficient plasma with or without HMW kininogen. $30 \mu \mathrm{l}$ of plasma plus $20 \mu \mathrm{l}$ of $1.6 \mathrm{U} / \mathrm{ml}$ purified HMW kininogen in a final volume of $60 \mu \mathrm{l}$ was incubated at $25^{\circ} \mathrm{C}$ for $10 \mathrm{~min} .30 \mu \mathrm{l}$ of buffer was substituted for the kininogen in the control. Electrophoresis was carried out for $1.5 \mathrm{~h}$ at $250 \mathrm{~V}$ at $14^{\circ} \mathrm{C}$ as described in Methods. The trough was filled with $100 \mu \mathrm{l}$ of 1:8 diluted anti-kallikrein antiserum. (1) Normal plus buffer; (2) normal plus HMW kininogen; (3) HMW kininogen-deficient plasma plus buffer; (4) H.MW kininogen-deficient plasma plus HMW kininogen. (B) IEP of purified prekallikrein and kallikrein with or without HMW kininogen. $30 \mu \mathrm{l}$ of purified prekallikrein $(1 \mathrm{U} / \mathrm{ml})$ or kallikrein $(1 \mathrm{U} / \mathrm{ml})$ was incubated with the same concentration of HMW kininogen and under the same conditions as Fig. 2A. Electrophoresis was carried out for $1.5 \mathrm{~h}$ at $250 \mathrm{~V}$ at $14^{\circ} \mathrm{C}$ as described in Methods. The trough was filled with $100 \mu \mathrm{l}$ of $1: 8$ diluted antikallikrein antiserum; PK, prekallikrein; KAL, kallikrein; HMWK, high molecular weight kininogen.
A dose response of prekallikrein-HMW kininogen formation was demonstrable by crossed IEP using purified components (Fig. 3). Purified prekallikrein (A) remained close to the origin resulting in a small symmetrical precipitin arc. Addition of $0.2 \mathrm{U} / \mathrm{ml} \mathrm{HMW} \mathrm{ki-}$ ninogen to the same amount of prekallikrein (B) resulted in a decrease of the arc corresponding to free prekallikrein, and the formation of a new precipitin arc migrating more anodally. The height and area of the new arc was further increased upon addition of $0.5 \mathrm{U} / \mathrm{ml} \mathrm{HMW}$ kininogen (C). This observation was similar to that seen on IEP.

The dependence of prekallikrein activity on HMW kininogen was also studied in HMW kininogen-deficient plasma (Fig. 4). In the prekallikrein coagulant assay, this plasma showed only $30 \%$ of normal activity. A dose-related increase in activity was noted when HMW kininogen was added to the plasma, reaching normal values at HMW kininogen concentrations of $\sim 0.2 \mathrm{U} / \mathrm{ml}$. HMW kininogen-deficient plasma showed no esterase activity after activation with kaolin for 1 min, as previously observed (1). When concentrations of HMW kininogen as high as $0.5 \mathrm{U} / \mathrm{ml}$ were added to the plasma before kaolin activation, $\sim 45 \%$ of the esterase activity as compared to the reference plasma was seen. However, if kallikrein inhibitors were depleted by treating the plasma with $\mathrm{CHCl}_{3}$ before addition of HMW kininogen at a concentration of 0.2 $\mathrm{U} / \mathrm{ml}$, normal levels of kallikrein esterase activity were attained.

Because HMW kininogen corrected the low prekallikrein antigen concentration in one individual's plasma with HMW kininogen deficiency, we sought to reevaluate the prekallikrein antigen levels in the plasma of other

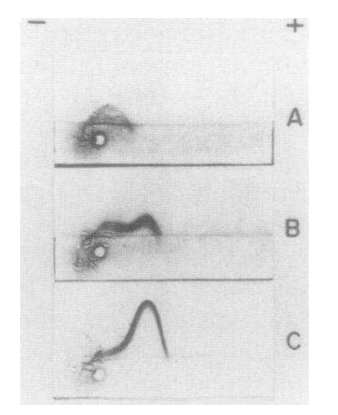

Figure 3 Crossed IEP-dose response of purified HMW kininogen on purified prekallikrein. $6 \mu \mathrm{g}$ of purified prekallikrein in $\mathrm{B}-2$ buffer $(\Gamma / 2=0.0375)$ was incubated alone $(\mathrm{A})$ or with $0.2 \mathrm{U} / \mathrm{ml}(\mathrm{B})$ or $0.5 \mathrm{U} / \mathrm{ml}$ purified HMW kininogen (C) for $10 \mathrm{~min}$ at $37^{\circ} \mathrm{C}$. Dimension 1 was run for $3.5 \mathrm{~h}$ at $250 \mathrm{~V}$ at $14^{\circ} \mathrm{C}$ on a single glass plate $(8.3 \times 9.4 \mathrm{~cm})$. After electrophoresis, the samples from dimension 1 (1.5-cm strips) were sliced and transferred to individual $3-\times 2$-in. microscope slides. Kallikrein antiserum for dimension 2 was used at a final concentration of $2.4 \%$. Electrophoresis in the second dimension was carried out for $16 \mathrm{~h}$ at $14^{\circ} \mathrm{C}$ at $50 \mathrm{~V}$. 


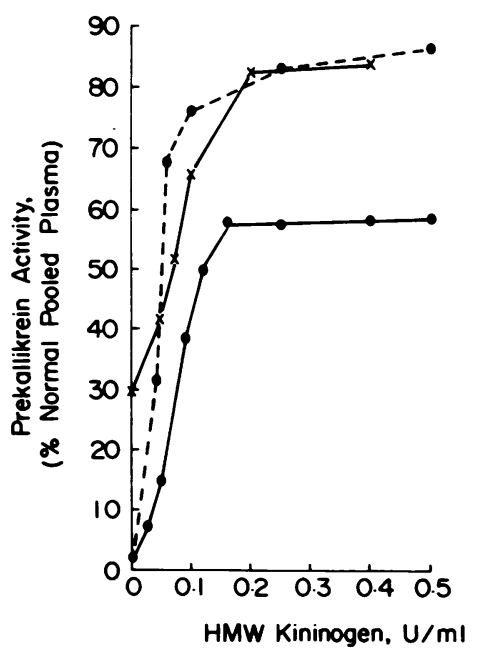

FIGURE 4 Effect of HMW kininogen on functional assays of prekallikrein from an HMW kininogen-deficient individual. HMW kininogen-deficient plasma was incubated with either buffer $(0.1 \mathrm{M}$ sodium phosphate, $\mathrm{pH} 7.6$, containing $0.15 \mathrm{M}$ $\mathrm{NaCl}$ for esterase assay, or sodium barbital buffer in saline, pH 7.4, for the clotting assay) or purified HMW kininogen for $10 \mathrm{~min}$ at $25^{\circ} \mathrm{C}$ and assayed as in methods: ( $\mathrm{CHCl}_{3}$-treated plasma (esterolytic activity); ( plasma (esterolytic activity); $(\times-\times)$ Native plasma (coagulant activity).

individuals with this deficiency (Table I). Four other individuals reported to have very low or undetectable levels of HMW kininogen were studied, in vitro, with and without HMW kininogen addition. In all cases, the concentration of prekallikrein antigen, as measured by RID, increased about twofold when HMW kininogen was added to the plasma $(0.5 \mathrm{U} / \mathrm{ml})$ before assay. Similar results were found when functional prekallikrein was measured in the four individuals. Prekallikrein coagulant assays performed by procedure $\mathrm{A}$ (Table I) revealed values ranging from 35 to $60 \%$ in the four HMW kininogen-deficient individuals' plasma. The prekallikrein coagulant activity rose to 73-93\% when HMW kininogen was added to the plasma sample before kaolin addition in the assay. Similar results were observed when the HMW kininogendeficient plasma was added to the prekallikreindeficient plasma before kaolin activation (procedure B). Therefore, it appears that the HMW kininogen deficiency was directly responsible for both the apparently low prekallikrein antigen concentration and functional activity previously observed in these individuals.

Because the addition of HMW kininogen affected the functional activity of prekallikrein in the plasma of HMW kininogen-deficient individuals, we proceded to evaluate the effect of additional HMW kininogen on the kallikrein esterase activity of 13 normal donors' native plasma as well as plasma in which the inhibitors were inactivated by $\mathrm{CHCl}_{3}$ treatment. Addition of 0.2
TABLE I

Correction of Apparent Prekallikrein Deficiency in HMW Kininogen-deficient Individuals

\begin{tabular}{|c|c|c|c|c|}
\hline & \multicolumn{4}{|c|}{ Prekallikrein } \\
\hline & \multicolumn{2}{|c|}{ No addition } & \multicolumn{2}{|c|}{$\begin{array}{l}\text { HMW kininogen } \\
\text { added* }\end{array}$} \\
\hline & Antigen 1 & $\begin{array}{l}\text { Coagulant } \\
\text { activity } \$\end{array}$ & Antigen $t$ & $\begin{array}{c}\text { Coagulant } \\
\text { activity }\end{array}$ \\
\hline Williams & 44 & 36 & 88 & 84 \\
\hline Mack & 43 & 47 & 72 & 73 \\
\hline C. $\mathbf{W}$. & 60 & 60 & 92 & 93 \\
\hline Fitzgerald & 35 & 35 & 70 & 83 \\
\hline Flaujeac & 63 & - & 110 & —" \\
\hline HMW kininogen & & & & \\
\hline$(0.5 \mathrm{U} / \mathrm{ml})$ & $<1$ & $<1$ & - & - \\
\hline
\end{tabular}

The above data represent the mean of three experiments.

* HMW kininogen (final concentration $0.5 \mathrm{U} / \mathrm{ml}$ or $33 \mu \mathrm{g} / \mathrm{ml}$ ) was incubated with plasma for $5 \mathrm{~min}$ at $37^{\circ} \mathrm{C}$ before preparing the assays.

$\$$ Prekallikrein antigen measured by RID and expressed as percent of normal pooled plasma.

$\S$ Prekallikrein coagulant activity is expressed as percent of normal pooled plasma.

"Insufficient plasma was available for prekallikrein coagulant assays after the antigen assays were completed.

U/ml HMW kininogen to native plasma increased the mean arginine esterase activity (kallikrein) from 102 to $132 \mu \mathrm{mol} \mathrm{TAMe} \mathrm{hydrolyzed/h}$ per $\mathrm{ml}(P<0.001$ by paired Student's $t$ test). The increase was uniform and the correlation of the activity in the native plasma with the activity in the same plasma supplemented with HMW kininogen was excellent $(r=0.91, P<0.001)$. If, however, esterase activity was measured in the plasma after $\mathrm{CHCl}_{3}$ treatment, the mean activity rose to $168 \mu \mathrm{mol}$ TAMe hydrolyzed/h per $\mathrm{ml}(P<0.001)$. There was a reasonable correlation between the activity in native and $\mathrm{CHCl}_{3}$-treated plasma $(r=0.66, P$ $<0.01$ ). However, in $\mathrm{CHCl}_{3}$-treated plasma no increase in esterase activity was noted after supplementation with HMW kininogen, suggesting that the naturally occurring kallikrein inhibitors were limiting the activation or activity. In fact, a small but statistically significant decrease to $152 \mu \mathrm{mol}$ TAMe hydrolyzed/h per $\mathrm{ml}$ $(P<0.001)$ was observed when additional HMW kininogen was added to the $\mathrm{CHCl}_{3}$-treated normal plasma. The results of this experiment are consistent with those of Kluft (21) who observed maximal activation of prekallikrein by kaolin in normal plasma at $20 \mathrm{~s}$ at $25^{\circ} \mathrm{C}$. A decrease of $30 \%$, observed at $1 \mathrm{~min}$, was attributed to inactivation of the kallikrein activity by plasma inhibitors such as Cî-inhibitor.

The effect of inhibitor is even more evident when $\mathrm{XII}_{\mathrm{f}}$ is used to activate purified prekallikrein (Fig. 5), in the fluid phase, in the absence of kaolin. As noted 


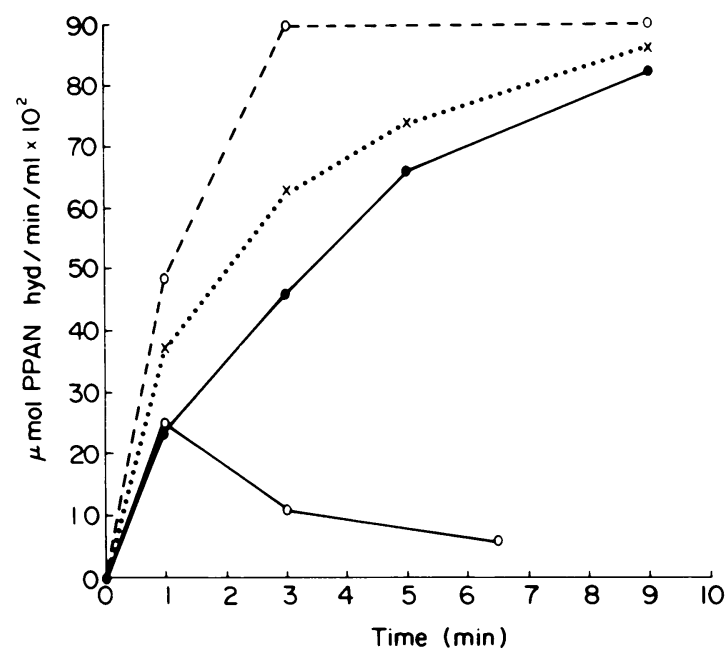

Figure $510 \mu \mathrm{l}(5 \mu \mathrm{g})$ of purified prekallikrein was incubated with $100 \mu \mathrm{l}$ of either buffer $(0.1 \mathrm{M}$ sodium phosphate, $\mathrm{pH} 7.6$, containing $0.15 \mathrm{M} \mathrm{NaCl}$ and $1 \mathrm{mg} / \mathrm{ml}$ bovine serum albumin), native prekallikrein-deficient plasma, or purified H.MW kininogen $(0.2 \mathrm{U} / \mathrm{ml})$ before addition of $20 \mu \mathrm{l}(1 \mu \mathrm{g})$ of $\mathrm{XII}_{\mathrm{f}} .10-\mu \mathrm{l}$ aliquots were assayed at various times for ability to hydrolyze H-D-Pro-Phe-Arg- $p$-nitroanilide-HCl (PPAN). (PK = prekallikrein); (O) PK plus buffer; $\left(\mathrm{O}_{-} \mathrm{O}\right)$ PK plus prekallikrein-deficient plasma (native); $\left(\mathrm{O}_{-}-\mathrm{O}\right) \mathrm{PK}$ plus prekallikrein-deficient plasma (acid-treated); (X) PK plus H.MW kininogen.

previously (9), the rate of prekallikrein activation by $\mathrm{XII}_{\mathrm{f}}$ is enhanced by purified HMW kininogen. However, when native prekallikrein-deficient plasma (a source of HMW kininggen and inhibitor but not prekallikrein) was added to purified prekallikrein and then activated by $\mathrm{XII}_{\mathrm{f}}$, a maximum of only $30 \%$ of its potential activity was reached as compared to the same amount of purified prekallikrein activated by $\mathrm{XII}_{\mathrm{f}}$ in the presence of buffer. A decrease in activity occurred after 1 min which was apparently a result of the inhibition of kallikrein activity by naturally occurring kallikrein inhibitors in the prekallikrein-deficient plasma. This hypothesis is confirmed by the finding that inactivation of inhibitors (by acid treatment) in the prekallikrein-deficient plasma before the addition of the purified prekallikrein and its subsequent activation by $\mathrm{XII}_{\mathrm{f}}$, resulted in rapid and complete activation of the prekallikrein. The level of activity in the prekallikrein-buffer mixture and the prekallikreinprekallikrein-deficient plasma (acid-treated) mixture was identical except that the latter attained the fully activated level at $3 \mathrm{~min}$ whereas even after $9 \mathrm{~min}$, the prekallikrein-buffer mixture had not reached full activation. The acceleration of the prekallikrein activation was a result of the presence of HMW kininogen and possibly other potentiators (23) derived from the prekallikrein-deficient plasma which were now free to operate without interference by plasma inhibitors. A mixture of purified prekallikrein and purified HMW kininogen $(0.2 \mathrm{U} / \mathrm{ml})$, after activation by $\mathrm{XII}_{\mathrm{f}}$, behaved similarly to the prekallikrein-prekallikrein-deficient plasma (acid-treated) mixture, in that, the rate of activation of the purified prekallikrein was accelerated by the presence of the HMW kininogen. This observation further supports the hypothesis that a deficiency of HMW kininogen in plasma can retard the rate of prekallikrein activation long enough to be significantly affected by plasma kallikrein inhibitors.

Because we observed free prekallikrein existing in normal plasma, in addition to complexed prekallikrein (Fig. 2), we sought to demonstrate whether it could form additional complex if combined with purified HMW kininogen and give rise to increased apparent prekallikrein antigen. Upon addition of purified HMW kininogen to normal pooled plasma, an increase in apparent prekallikrein concentration was observed both in RID (35\%) and EID (50\%) (Fig. 6). Further evidence was seen when normal plasma from a single donor was gel filtered (Fig. 7). Two peaks of prekallikrein coagulant activity were found. One peak, in the area of the previously described complex (24) having an $M_{r}$ of $\sim 280,000$ daltons, represented $\sim 89 \%$ of the total prekallikrein coagulant activity, whereas the other activity peak was observed in the area of free prekallikrein $\left(M_{r} 120,000\right)$. Addition of the column fraction to the prekallikrein-deficient plasma before kaolin addition in the prekallikrein coagulant assay, resulted in a twofold increase of activity in the $120,000 M_{r}$ peak. Because the prekallikrein-deficient plasma contains HMW kininogen, it allowed the formation of the prekallikrein-HMW kininogen complex with the free prekallikrein in the column fractions. The effect is similar

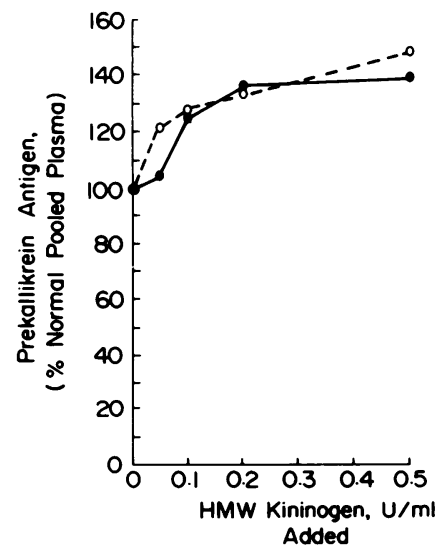

FIGURE 6 Effect of HMW kininogen on the immunologic assays of plasma prekallikrein in normal pooled plasma. Plasma was incubated with B-2 buffer or purified HMW kininogen for $10 \mathrm{~min}$ at $37^{\circ} \mathrm{C}$ before assay by either EID or RID. A standard curve was prepared from a sample of normal pooled plasma. The values are expressed as percent of normal pooled plasma; (O) EID; (O) RID. 


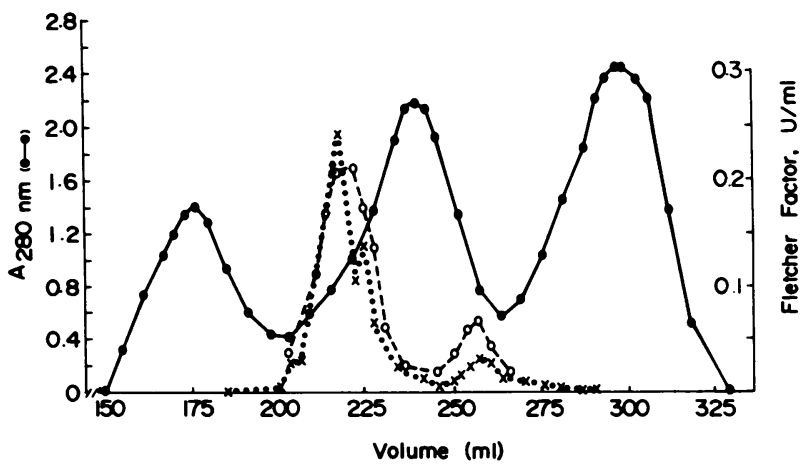

FIGURE 7 Gel filtration of native, normal plasma. $4 \mathrm{ml}$ of plasma from a single donor was gel filtered on Sephadex G-200 in $0.01 \mathrm{M}$ Tris-Cl, $\mathrm{pH} 8$, containing $0.15 \mathrm{M} \mathrm{NaCl}$ and $0.02 \%$ sodium azide at room temperature. Protein was determined by absorbance at $280 \mathrm{~nm}$. (-) Prekallikrein coagulant activity (Fletcher factor) was measured by either adding the kaolin mixture to the sample before the prekallikreindeficient plasma $(x)$ procedure $A$, or by adding the sample to the prekallikrein-deficient plasma before the kaolin addition (O) procedure B. 3-ml fractions were collected. Column $=2.5 \times 90 \mathrm{~cm}$, flow $=12 \mathrm{ml} / \mathrm{h}$.

to adding purified HMW kininogen to the sample before kaolin addition. The apparent prekallikrein coagulant activity in that peak then increased to $\sim 17 \%$ of the total. However, no augmentation of prekallikrein coagulant activity was obtained in the region of the complex. No increase in prekallikrein coagulant activity was observed if kaolin was added before the prekallikrein-deficient plasma. Similar results were obtained in plasma from three other donors. Free plasma prekallikrein ranged from 17 to $38 \%$ of the total prekallikrein recovered after gel filtration.

Because many of the experiments in this study were performed using frozen plasma (HMW kininogen-deficient plasma and normal pooled plasma), we tested whether freezing the plasma had caused in vitro (artefactual) dissociation of the complex generating free prekallikrein. Two types of observations suggested that this was not the case. (a) Gel filtration of fresh or frozen plasma from the same donor yielded essentially the same distribution of prekallikrein coagulant activity. (b) The fresh plasma from five normal donors, subjected to IEP, revealed the double arc characteristic of both complexed and free prekallikrein. Freezing and thawing the same five plasma samples did not alter the immunoelectrophoretic pattern of the prekallikrein antigen (data not shown). Thus, free prekallikrein and prekallikrein-HMW kininogen complex probably exist in an equilibrium in normal plasma.

\section{DISCUSSION}

The occurrence of multiple apparent defects in the hemostatic system is not unique to the contact phase.
Combined Factor V and Factor VIII deficiencies are documented (25) and the complexities of the overlapping defects in hemophilia A and von Willebrand's disease are well known (26). Several explanations have been offered to account for the combined deficiency of HMW kininogen and prekallikrein including genetic linkage (27). Nevertheless, the possibility must be considered that functional or structural relationships between these two proteins might directly influence assay methods. Although the major defect in the HMW kininogen-deficient individuals $(1-5,28)$ is the deficiency of HMW kininogen, all but one (3) (prekallikrein coagulant activity $=65 \%$ ) have been reported to have decreased prekallikrein as measured by coagulant activity, antigen, and/or kaolin-activated arginine esterase activity.

Recent studies have suggested that prekallikrein and HMW kininogen exist as a complex in native plasma. Mandle et al. (24) gel filtered normal plasma and demonstrated a complex of HMW kininogen and prekallikrein of $M_{r} 315,000$. Donaldson et al. (27) confirmed the existence of the complex by adsorbing both prekallikrein and HMW kininogen from plasma with either monospecific antiserum against kallikrein or HMW kininogen. Furthermore, both proteins are important for optimal activation $(7,8)$ and activity (9) of the various forms of Factor XII.

Our experiments demonstrate both qualitative and quantitative modification of prekallikrein antigen migration and reactivity both in purified preparations as well as in normal and HMW kininogen-deficient plasma by the addition of purified HMW kininogen. Observations of the immunoelectrophoretic pattern of purified prekallikrein or plasma deficient in HMW kininogen revealed a single, discrete precipitin arc, which is in agreement with the observations of Donaldson et al. (27). We were able to demonstrate, however, that the addition of purified HMW kininogen extended the precipitin arc anodally while retaining antigenic identity to the more cathodal arc, similar to the pattern observed in normal plasma. Moreover, further addition of HMW kininogen decreased the free prekallikrein arc while augmenting the area under the arc of the complex, as measured by crossed IEP.

Both EID and RID showed increasing apparent antigen concentrations proportional to the amount of HMW kininogen added. In the EID technique, enhanced migration of the more anionic complex, compared to free prekallikrein, may be partly responsible for the apparent increase in antigen level, although this phenomenon would not explain the increased size of the precipitin ring observed in RID. Because the complex is larger, one might expect a decrease of the precipitin ring as compared to the same concentration of free prekallikrein if the measurement were made at a fixed time interval. By measuring the maximum ring diameter, 
we assured that the size of the complex was not limiting. The cause of the larger ring diameter of the complex is unknown but may be the result of an alteration in the number of exposed antigenic sites in the complex (for example, prekallikrein enclosing a HMW kininogen core) or to conformational changes in the complexed molecule resulting in changes in its molecular dimensions. To detect neoantigenic sites, the prekallikrein antibody was adsorbed with HMW kininogendeficient plasma. However, the adsorbed antiserum still recognized both free prekallikrein and prekallikrein-HMW kininogen complex although the titer appeared diminished. Crossed IEP, however, suggested that the antigenic reactivity of the complex is different from free prekallikrein because the height and integrated area of the complex was increased with increasing amounts of HMW kininogen. Thus, it appears that the apparent deficiency of prekallikrein antigen in HMW kininogen-deficient plasma was a result of the absence of HMW kininogen and not prekallikrein.

Although decreased functional prekallikrein activity has previously been reported in three individuals ( 1 , 2 , and 4), we found normal prekallikrein levels to be present in the plasma of these individuals if we performed the assays after inactivating plasma inhibitors and then supplementing it with HMW kininogen. The presence of inhibitors was also a determinant of the extent of prekallikrein activation and kallikrein activity in normal plasma. Kallikrein esterase activity was higher in plasma depleted of kallikrein inhibitors than in native plasma, although the two measurements remained closely correlated. Thus, activation of native plasma prekallikrein by kaolin for $1 \mathrm{~min}$ at $25^{\circ} \mathrm{C}$ gave an estimate of total prekallikrein but actually underestimated the absolute concentration. The addition of HMW kininogen to normal native plasma may augment kallikrein esterase levels by increasing the rate of activation, in part, by forming additional complex with the free prekallikrein. However, the failure of $\mathrm{HMW}$ kininogen to augment prekallikrein activation in $\mathrm{CHCl}_{3}$ treated plasma suggests another role for the cofactor. It is possible that when HMW kininogen binds to kallikrein, it retards the destruction of the kallikrein activity by competing for binding sites that would otherwise be available to $C \overline{1}$-inhibitor. The importance of plasma inhibitors is underscored when activation proceeds more slowly exemplified by the experiments using XII $_{\mathrm{f}}$ and purified prekallikrein.

The concept of free prekallikrein existing in equilibrium with the prekallikrein-HMW kininogen complex was supported by the observation of a $120,000-M_{r}$ peak on gel filtration of normal plasma in addition to the predominant $280,000-M_{r}$ peak previously reported by Mandle et al. (24). Differences in methodology of the prekallikrein coagulant assay may explain the failure of Mandle et al. (24) to note the uncomplexed pre- kallikrein, although a peak representing $11 \%$ of the activity could easily have been missed. Further evidence of free as well as complexed prekallikrein in normal plasma was observed on IEP in both fresh and frozen plasma.

The data suggest that assays of plasma prekallikrein alone do not assure accurate quantitation unless a concentration of at least $0.2 \mathrm{U} / \mathrm{ml}$ HMW kininogen is intrinsically present in the sample or is added to the assay system. The absence of HMW kininogen results in apparently low prekallikrein levels because of $(a)$ incomplete surface activation in the coagulant assay; (b) incomplete activation coupled with greater inhibition in the esterolytic and amidolytic assays; and $(c)$ decreased antigenic reactivity.

\section{ACKNOWLEDGMENTS}

We wish to thank Ms. Penny Shames for furnishing us with purified high molecular weight kininogen. We also wish to thank Ms. Rose Payton, Ms. Lisa Spiller, and Ms. Terry Cruice for typing this manuscript.

This investigation was supported, in part, by National Institutes of Health grant HL 24365.

\section{REFERENCES}

1. Colman, R. W., A. Bagdasarian, R. C. Talamo, C. F. Scott, M. Seavey, J. A. Guimaraes, J. V. Pierce, and A. P. Kaplan. 1975. Williams trait. Human kininogen deficiency with diminished levels of plasminogen proactivator and prekallikrein associated with abnormalities of the Hageman factor-dependent pathway.J. Clin. Invest. 56: 1650-1662.

2. Saito, H., O. D. Ratnoff, R. Waldmann, and J. P. Abraham. 1975. Fitzgerald trait. Deficiency of a hitherto unrecognized agent, Fitzgerald factor, participating in surfacemediated reactions of clotting, fibrinolysis, generation of mediated kinins, and the property of diluted plasma enhancing vascular permeability $(\mathrm{PF} / \mathrm{dil})$. J. Clin. Invest. 55: $1082-1089$.

3. Wuepper, K. D., D. R. Miller, and M. J. Lacombe. 1975. Flaujeac trait. Deficiency of human plasma kininogen. J. Clin. Invest. 56: 1663-1672.

4. Donaldson, V. H., H. I. Glueck, M. A. Miller, H. Z. Movat, and F. Habal. 1976. Kininogen deficiency in Fitzgerald trait: role of high molecular weight kininogen in clotting and fibrinolysis. J. Lab. Clin. Med. 87: 327-337.

5. Lutcher, C. L. 1976. Reid trait: a new expression of high molecular weight kininogen (HMW-kininogen) deficiency. Clin. Res. 24: 47A. (Abstr.)

6. Jacobsen, S., and M. Kritz. 1967. Some data on two purified kininogens from human plasma. Br.J. Pharmacol. 29: 25-36.

7. Griffin, J., and C. G. Cochrane. 1976. Mechanisms for the involvement of high molecular weight kininogen in surface-dependent reaction of Hageman factor. Proc. Natl. Acad. Sci. U. S. A. 73: 2554-2558.

8. Meier, M. L., J. V. Pierce, R. W. Colman, and A. P. Kaplan. 1977. Activation and function of human Hageman factor. The role of high molecular weight kininogen and prekallikrein. J. Clin. Invest. 60: 18-31.

9. Liu, C. Y., C. F. Scott, A. Bagdasarian, J. V. Pierce, A. P. Kaplan, and R. W. Colman. 1977. Potentiation of the function of Hageman factor fragments by high molecular weight kininogen. J. Clin. Invest. 60: 7-17. 
10. Scott, C. F., C. Y. Liu, and R. W. Colman. 1979. Human plasma prekallikrein: a rapid high-yield method for purification. Eur. J. Biochem. 100: 77-83.

11. Weber, K., and M. Osborn. 1969. The reliability of molecular weight determintion by sodium dodecyl sulfate polyacrylamide gel electrophoresis. J. Biol. Chem. 244: 44064412.

12. Habal, F. M., and H. Z. Movat. 1976. Rapid purification of human high molecular weight kininogen. Agents Actions. 6: 565-8.

13. Bagdasarian, A., R. C. Talamo, and R. W. Colman. 1973. Isolation of high molecular weight activators of human plasma kallikrein. J. Biol. Chem. 248: 3456-3463.

14. Bagdasarian, A., B. Lahiri, R. C. Talamo, P. Wong, and R. W. Colman. 1974. Immunochemical studies of plasma kallikrein. J. Clin. Invest. 54: 1444-1454.

15. Laurell, C. B. 1966. Quantitative estimation of proteins by electrophoresis in agarose gel containing antibodies. Anal. Biochem. 15: 45-52.

16. Colman, R. W., R. Edelman, C. F. Scott, and R. M. Gilman. 1978. Plasma kallikrein activation in typhoid fever.J. Clin. Invest. 61: 287-296.

17. Mancini, G., A. O. Carbonaro, and J.F. Heremans. 1965. Immunochemical quantitation of antigens by single radial immunodiffusion. Immunochemistry. 2: 235-254.

18. Siegelman, A. M., A. S. Carlson, and T. Robertson. 1962. Investigation of serum trypsin and related substances. I. The quantitative demonstration of trypsinlike activity in human blood serum by a micromethod. Arch. Biochem. Biophys. 97: 159-163.

19. Colman, R. W., J. W. Mason, and S. Sherry. 1969. The kallikreinogen-kallikrein enzyme system of human plasma. Assays of components and observations in disease states. Ann. Intern. Med. 71: 763-773.

20. Colman, R. W., L. Mattler, and S. Sherry. 1969. Studies on the prekallikrein-(kallikreinogen)-kallikrein enzyme system of human plasma. II. Evidence relating the kaolinactivation arginine esterase to plasma kallikrein. J. Clin. Invest. 48: 23-32.

21. Kluft, C. 1978. Determination of prekallikrein in human plasma: optimal conditions for activating prekallikrein. J. Lab. Clin. Med. 91: 83-95.

22. Proctor, R. R., and S. J. Rapaport. 1961. The partial thromboplastin time with kaolin: a simple screening test for first stage plasma clotting deficiencies. Am.J. Clin. Pathol. 35: 212-219.

23. Colman, R. W., C. F. Scott, V. Dayal, P. V. Shames, C. Y. Liu, and E. P. Kirby. 1980. Prekallikrein activation of Hageman factor: potentiation by proteins in the absence of high molecular weight kininogen. Trans. Assoc. Am. Phys. In press.

24. Mandle, R., R. W. Colman, and A. P. Kaplan. 1976. Identification of prekallikrein and high-molecular-weight kininogen as a complex in human plasma. Proc. Natl. Acad. Sci. U. S. A. 73: 4179-4183.

25. Iversen, T., and P. Bastrup-Madsen. 1956. Congenital familial deficiency of factor $V$ (parahemophilia) combined with deficiency of antihemophilia globulin. Br. J. Haematol. 2: 265-271.

26. Green, D., and J. R. Chediak. 1977. von Willebrand's disease: current concepts. Am. J. Med. 62: 315-318.

27. Donaldson, V. M., J. Kleniewski, H. Saito, and J. K. Sayed. 1977. Prekallikrein deficiency in a kindred with kininogen deficiency and Fitzgerald trait clotting defect. Evidence that high molecular weight kininogen and prekallikrein exist as a complex in normal human plasma. J. Clin. Invest. 60: 571-583.

28. Oh-ishi, S., A. Ueno, Y. Uchida, M. Katori, H. Hayashi, H. Koya, K. Kitajima, and I. Kimura. 1979. Fujiwara trait. The first case of kininogen deficiency in Japan. International Symposium of Kinins, Tokyo, Japan. 